\title{
HUBUNGAN BEKERJA JARAK JAUH DAN KOMUNIKASI DENGAN PENJADWALAN PROYEK DI KAWAN LAMA RETAIL
}

\author{
Angga Pratama ${ }^{1}$ dan Wahyu Indra Sakti Saidi ${ }^{2}$
}

\author{
${ }^{1}$ Prodi Teknik Sipil, Universitas Tarumanagara, Jl. Letjen S. Parman No 1, Jakarta, 11440 \\ Email korespondensi: angga_prat@yahoo.co.id \\ 2 Prodi Teknik Sipil, Universitas Tarumanagara, Jl. Letjen S. Parman No 1, Jakarta, 11440 \\ Email : wahyusaidi@gmail.com
}

\begin{abstract}
ABSTRAK
Penjadwalan proyek dikatakan sesuai dengan rencana jika terlaksana sesuai dengan target yang telah ditentukan. Penjadwalan pada proyek merupakan salah satu elemen dari hasil perencanaan, yang dapat memberikan informasi tentang jadwal rencana dan kemajuan proyek dalam hal kinerja sumber daya berupa biaya, tenaga kerja, peralatan dan material serta rencana durasi dan progress waktu untuk penyelesaian proyek, Proses pemantauan serta pembaruan selalu dilakukan untuk mendapatkan penjadwalan yang paling realistis agar alokasi sumber daya dan penetapan durasinya sesuai dengan sasaran dan tujuan proyek. Penelitian ini menggunakan metode kuesioner dalam pencarian data. Sampel yang digunakan adalah karyawan yang bekerja di Kawan Lama Retail sejumlah 32 orang dengan menggunakan metode simple random sampling. Penelitian ini hanya dibatasi pada analisis mengenai hubungan bekerja jarak jauh dan komunikasi terhadap penjadwalan proyek di Kawan Lama Retail. Metode analisis yang digunakan adalah uji validitas, uji reliabilitas, analisis determinasi, analisis regresi dan korelasi baik sederhana maupun berganda. Sehingga melalui metode ini dapat diketahui seberapa besar hubungan bekerja jarak jauh dan komunikasi terhadap penjadwalan proyek di Kawan Lama Retail. Dari hasil penelitian, menunjukkan bahwa terdapat hubungan positif dan signifikan antara bekerja jarak jauh dan komunikasi secara bersama-sama dengan penjadwalan proyek. Dengan kata lain jika tidak ada peningkatan dalam bekerja jarak jauh dan komunikasi yang baik maka penjadwalan tidak akan memenuhi target yang ada. Namun perlu diperhatikan bahwa konstanta penjadwalan proyek mempunyai nilai negatif, dimana jika dalam bekerja jarak jauh dan komunikasi tidak diperhatikan dengan baik, maka penjadwalan proyek di Kawan Lama Retail tidak akan berjalan sesuai dengan target.
\end{abstract}

Kata Kunci : Bekerja Jarak Jauh, Komunikasi, Penjadwalan Proyek

\begin{abstract}
A Project schedule is said to be in accordance with the plan if carried out according to predetermined targets. Project scheduling is one of the elements of the planning results, which can provide information about the planned schedule and project progress in terms of resource performance in the form of costs, labor, equipment, and materials as well as duration plans and time progress for project completion, monitoring and updating processes always. Carried out to get the most realistic scheduling so that the allocation of resources and determination of their duration is in accordance with the goals and objectives of the project. This research method using the questionnaire in the search data. The sample used is employees who work at Kawan Lama Retail as many as 32 people using the simple random sampling method. This research is only limited to the analysis of the relationship between telecommuting and communication with project scheduling at Kawan Lama Retail. The method of analysis used is test validity, test reliability, determination of the test analysis, regression analysis, and correlation both simple and double. So that through this method can be seen how big the relationship of telecommuting and communication in project scheduling at Kawan Lama Retail. The research results, showing that there is a positive and significant relationship between telecommuting and communication with project scheduling. in other words, if there is no improvement in remote working and good communication, the scheduling will not meet the existing targets. However, it should be noted that
\end{abstract}


the constant project scheduling has a negative value, where if in telecommuting and communication is not paid attention to properly, the project scheduling at Kawan Lama Retail not run according to the target.

Keywords: Telecommuting, Communication, Project Scheduling

\section{PENDAHULUAN}

Kawan Lama Retail adalah perusahaan penyedia peralatan industri yang berkantor pusat di Meruya Kembangan Jakarta Barat. Perusahaan ini menyediakan berbagai macam peralatan industri mulai dari alat rumah tangga sampai alat-alat bengkel. Kawan Lama Retail telah berdiri sejak tahun 1955 dan sampai saat ini sudah memiliki beberapa bidang yang bergerak dalam sektor retail, Industrial, Food and Beverage, Service, Properti dan E-commerce. Selama lebih dari setengah abad, kawan lama terus bertumbuh dan berkembang hingga menaungi lebih dari 40.000 karyawan. Dengan semakin banyaknya produk yang dipasarkan dan agar lebih fokus melayani dan memenuhi kebutuhan maka diluncurkan lah Grup Kawan Lama Retail yang terdiri dari : PT Ace Hardware Indonesia, PT Informa Furnishings, Chatime.

Di kantor pusat Kawan Lama Retail mempunyai divisi Site Development \& Project Management, Site Development bertugas sebagai Meriset pasar, mencari peluang pelanggan baru, dan menjaga hubungan dengan pelanggan. Bekerja Sama dengan divisi lain seperti divisi teknis untuk memenuhi kebutuhan pelanggan/pasar. Menyusun dan mempresentasikan rencana pengembangan bisnis perusahaan. Update pengetahuan mengenai perkembangan pasar serta kompetitor. Melakukan riset perkembangan bisnis perusahaan secara berkala. Sangat penting perannya dalam perkembangan dan kemajuan sebuah Bisnis, karena jika salah memilih lokasi dan salah menentukan titik berpotensi akan menimbulkan kerugian terutama pada bisnis retail. Semakin banyak jumlah jaringan toko atau cabang maka akan mendapatkan atau meningkatkan potensi keuntungan. Untuk perkembangan dan kemajuan toko design interior penting untuk menarik perhatian pengunjung. Desain interior adalah salah satu cabang seni rupa yang fokus terhadap perancangan ruang dalam suatu bangunan, gunanya bukan lain adalah untuk memperbaiki fungsi bagaimana ruangan tersebut dapat dimanfaatkan dengan baik, Setiap desain bertujuan menyusun secara teratur bagian demi bagian menjadi satu tatanan yang utuh untuk maksud-maksud tertentu, Akan tetapi konstruksi interior ini memiliki jangka waktu yang pendek/cepat sehingga membutuhkan penjadwalan yang baik. Mulai dari perencanaan gambar sampai dengan perhitungan biaya dari proyek tersebut, Di Kawan Lama sudah merencanakan waktu pembuatan design, perhitungan sampai dengan pelaksanaan di lapangan apabila terjadi keterlambatan maka akan mempengaruhi waktu penyelesaian suatu proyek.

Dalam masa pandemi sekarang Pemerintah mengadakan Pembatasan Sosial Berskala Besar (PSBB) yang merupakan keputusan pemerintah dalam langkah dan upaya pencegahan virus corona (covid-19) ini mengakibatkan karyawan harus bekerja jarak jauh, Dalam masa pandemi ini Kawan Lama Retail tetap akan membuka banyak toko baru sesuai dengan target yang. Agar proses pembuatan design interior dan pelaksanaan perhitungan proyek tersebut sesuai dengan penjadwalan pembukaan toko berjalan sesuai dengan target diperlukan penjadwalan dan komunikasi yang bagus agar tidak terganggu dengan adanya bekerja jarak jauh atau work from home. 


\section{TINJAUAN PUSTAKA}

Bekerja jarak jauh bisa di sebut juga sebagai telecommuting atau telekomunikasi atau bisa diartikan lain yaitu melakukan pekerjaan yang biasa dilakukan di kantor dari rumah. Jadi pekerja tidak harus pulang pergi ke kantor, adanya jam kerja yang flexible, kebebasan untuk berpakaian, dan hanya terdapat sedikit atau tidak sama sekali gangguan dari para kolega. Bekerja dari rumah juga suatu model kerja dimana karyawan memperoleh fleksibilitas bekerja dalam hal tempat dan waktu kerja dengan bantuan dari telekomunikasi atau telecommuting. Telekomunikasi merupakan jenis pekerjaan yang dapat dilakukan di lokasi yang tidak membutuhkan banyak waktu untuk pergi dan pulang ke tempat kerja, pekerjaan yang dapat dilakukan di dalam rumah atau di lokasi kerja yang lain, dan di fasilitasi oleh jaringan internet dan komputer. Telekomunikasi juga didefinisikan sebagai kemampuan untuk melakukan pekerjaan di lokasi selain dari kantor, yang dilakukan secara rutin, teratur, dan dilakukan lebih dari satu hari dalam sepekan Jam kerja karyawan telecommute bervariasi, mulai dari hanya beberapa jam di luar kantor dalam sepekan, hingga sepenuhnya berada di luar. Ada tiga kategori pekerjaan yang dapat dikerjakan dengan telekomunikasi yaitu pekerjaan yang mengelola informasi secara rutin, pekerjaan yang membutuhkan aktivitas banyak berpindah tempat, serta tugas-tugas professional atau pekerjaan yang membutuhkan pengetahuan spesifik untuk mengerjakannya.

Komunikasi secara umum berasal dari bahasa Latin communication yang berarti pemberitahuan atau pertukaran pikiran, secara garis besar dalam suatu proses komunikasi haruslah terdapat unsur-unsur kesamaan makna agar terjadi suatu pertukaran pikiran dan pengertian antara komunikator/penyebar pesan dan komunikan/penerima pesan. dalam proses komunikasi dapat diartikan sebagai transfer informasi atau pesan dari pengirim pesan sebagai komunikator dan kepada penerima sebagai komunikan. Dalam proses komunikasi tersebut bertujuan untuk mencapai saling pengertian antara kedua pihak yang terlibat dalam proses komunikasi. Komunikasi merupakan salah satu dari kegiatan sehari-hari yang terhubung dengan semua kegiatan kemanusiaan, setiap aspek kehidupan kita dipengaruhi oleh komunikasi kita dengan orang lain, komunikasi merupakan sebuah proses menyamakan dua atau beberapa hal mengenai kekuasaan terhadap seseorang atau beberapa orang, komunikasi dikatakan berhasil jika komunikasi merupakan pertukaran sebuah pemikiran atau gagasan. Asumsi dalam definisi ini adalah bahwa sebuah pemikiran atau gagasan berhasil ditukarkan, ada yang berpendapat bahwa komunikasi merupakan sebuah proses dalam penyampaian pesan dari komunikator kepada komunikan melalui saluran tertentu

Penjadwalan pada proyek merupakan salah satu elemen dari hasil perencanaan, yang dapat memberikan informasi tentang jadwal rencana dan kemajuan proyek dalam hal kinerja sumber daya berupa biaya, tenaga kerja, peralatan dan material serta rencana durasi dan progress waktu untuk penyelesaian proyek. Dalam proses penjadwalan, penyusunan kegiatan dan hubungan antar kegiatan dibuat lebih terperinci dan sangat detail. Hal ini dimaksudkan untuk membantu pelaksanaan evaluasi proyek. Penjadwalan adalah pengalokasian waktu yang tersedia untuk menyelesaikan suatu proyek hingga tercapai hasil optimal dengan mempertimbangkan keterbatasan-keterbatasan yang ada. Pada proses pengendalian proyek, penjadwalan mengikuti perkembangan proyek dengan berbagai permasalahannya. Proses pemantauan serta pembaruan selalu dilakukan untuk mendapatkan penjadwalan yang paling realistis agar alokasi sumber daya dan penetapan durasinya sesuai dengan sasaran dan tujuan proyek. 


\section{METODE PENELITIAN}

Pada Penelitian jenis yang digunakan untuk meneliti hubungan antara bekerja jarak jauh dan komunikasi terhadap penjadwalan di proyek Kawan Lama Retail adalah bersifat analisis parametric dan deskriptif. Analisis parametric digunakan untuk mengetahui hubungan variabel bebas dan variabel terikat dalam penelitian ini. Sedangkan penelitian deskriptif ini menggunakan suatu metode yang bertujuan untuk memberikan gambaran tentang masing-masing variabel yang sedang di teliti.

Variabel yang diteliti adalah bekerja jarak jauh dan komunikasi sebagai variabel bebas atau variabel $\mathrm{X}$ dan penjadwalan di proyek Kawan Lama Retail sebagai variabel terikat atau variabel Y. Pola hubungan yang akan dikaji dalam penelitian ini dapat dilihat pada struktur hubungan bekerja jarak jauh dan komunikasi terhadap penjadwalan di proyek Kawan Lama Retail. Dari pola di atas, maka diperoleh gambaran bahwa yang dikaji penulis adalah sejauh mana kedua variabel bebas X1 dan X2 mempengaruhi variabel terikat Y.

\section{ANALISIS DAN PEMBAHASAN}

Responden yang digunakan sebanyak 32 karyawan di Kawan Lama Retail yang terdiri dari designer dan quantity surveyor. Data responden tersebut akan dilakukan analisis statistik deskriptif untuk lebih dapat diketahui secara jelas mengenai frekuensi data responden, analisis dilakukan dengan menggunakan program statistik. Analisis data mencakup statistik deskriptif dan parametrik, statistik deskriptif akan menggambarkan secara ringkas mengenai suatu data.

\section{Data umum responden}

Tabel 1. Frekuensi Responden Berdasarkan Jenis Kelamin

\begin{tabular}{crrrr}
\hline & $\begin{array}{c}\text { Frequ } \\
\text { ency }\end{array}$ & Percent & $\begin{array}{c}\text { Valid } \\
\text { Percent }\end{array}$ & $\begin{array}{c}\text { Cumulative } \\
\text { Percent }\end{array}$ \\
\hline $\begin{array}{c}\text { Laki }- \\
\text { Laki }\end{array}$ & 16 & 50.0 & 50.0 & 50.0 \\
\hline
\end{tabular}

\begin{tabular}{crrrr}
\hline & $\begin{array}{c}\text { Frequ } \\
\text { ency }\end{array}$ & Percent & $\begin{array}{c}\text { Valid } \\
\text { Percent }\end{array}$ & $\begin{array}{c}\text { Cumulative } \\
\text { Percent }\end{array}$ \\
\hline Wanita & 16 & 50.0 & 50.0 & 50.0 \\
\hline Total & 32 & 100.0 & 100.0 & \\
\hline
\end{tabular}

Berdasarkan tabel 1 maka jumlah responden laki-laki yaitu sebanyak 16 orang $(50 \%)$, dan responden wanita yaitu sebanyak 16 orang (50\%).

Tabel 2. Frekuensi Responden Berdasarkan Usia

\begin{tabular}{lrrrr}
\hline & $\begin{array}{c}\text { Freque } \\
\text { ncy }\end{array}$ & $\begin{array}{c}\text { Perce } \\
\text { nt }\end{array}$ & $\begin{array}{c}\text { Valid } \\
\text { Percent }\end{array}$ & $\begin{array}{c}\text { Cumulative } \\
\text { Percent }\end{array}$ \\
\hline $\begin{array}{l}17-24 \\
\text { tahun }\end{array}$ & 1 & 3.1 & 3.1 & 3.1 \\
\hline $25-34$ & 28 & 87.5 & 87.5 & 90.6 \\
tahun & & & & \\
\hline $\begin{array}{l}\text { 34- } 44 \\
\text { tahun }\end{array}$ & 3 & 9.4 & 9.4 & 100.0 \\
\hline Total & 32 & 100.0 & 100.0 & \\
\hline
\end{tabular}

Berdasarkan tabel 2 terbesar dalam penelitian adalah usia 25-34 tahun yaitu sebanyak 28 orang $(87.5 \%)$ dan responden terkecil adalah responden yang berusia 1724 tahun yaitu sebanyak 1 orang (3.1). Responden lainnya berusia 34-44 tahun adalah sebanyak 3 orang (9.4\%).

Tabel 3. Frekuensi Responden Berdasarkan Tingkat Pendidikan

\begin{tabular}{lrrrr}
\hline & $\begin{array}{c}\text { Frequ } \\
\text { ency }\end{array}$ & $\begin{array}{c}\text { Percen } \\
\boldsymbol{t}\end{array}$ & $\begin{array}{c}\text { Valid } \\
\text { Percent }\end{array}$ & $\begin{array}{c}\text { Cumulative } \\
\text { Percent }\end{array}$ \\
\hline SMA & 2 & 6.3 & 6.3 & 6.3 \\
\hline S1 & 30 & 93.8 & 93.8 & 100.0 \\
\hline Total & 32 & 100.0 & 100.0 & \\
\hline
\end{tabular}

Berdasarkan tabel 3 responden terbesar dalam penelitian adalah tingkat pendidikan S1 yaitu sebanyak 30 orang (93.8\%), dan responden lainnya yang mempunyai pendidikan SMA/Sederajat adalah sebanyak 2 orang $(6.3 \%)$. 
Tabel 4. Frekuensi Responden Berdasarkan Lama Bekerja

\begin{tabular}{lrrrr}
\hline & $\begin{array}{c}\text { Freque } \\
\text { ncy }\end{array}$ & $\begin{array}{c}\text { Percen } \\
\text { t }\end{array}$ & $\begin{array}{c}\text { Valid } \\
\text { Percent }\end{array}$ & $\begin{array}{c}\text { Cumulative } \\
\text { Percent }\end{array}$ \\
\hline $\begin{array}{l}1-3 \\
\text { Tahun }\end{array}$ & 9 & 28.1 & 28.1 & 28.1 \\
\hline 3 - 5 & 7 & 21.9 & 21.9 & 50.0 \\
Tahun & & & & \\
\hline $\begin{array}{l}\text { < } 5 \\
\text { Tahun }\end{array}$ & 16 & 50.0 & 50.0 & 100.0 \\
\hline Total & 32 & 100.0 & 100.0 & \\
\hline
\end{tabular}

Berdasarkan Tabel 4 responden terbesar dalam penelitian adalah lebih dari 5 tahun yaitu sebanyak 16 orang (50\%), dan responden terkecil adalah 3-5 tahun yaitu 7 orang (21.9\%). Responden lainnya dengan lama bekerja 1-3 tahun yaitu 9 orang $(28,1 \%)$.

\section{Uji validitas dan reabilitas}

Tabel 5. Hasil Uji Validitas Bekerja Jarak Jauh

\begin{tabular}{cccc}
\hline $\begin{array}{c}\text { Nomor } \\
\text { Pertanyaan }\end{array}$ & $\begin{array}{r}\boldsymbol{r} \\
\text { hitung }\end{array}$ & $\begin{array}{c}\boldsymbol{r} \\
\text { tabel }\end{array}$ & \\
\hline $\mathrm{X}_{1}-1$ & 0,773 & 0,349 & Valid \\
\hline $\mathrm{X}_{1}-2$ & 0,655 & 0,349 & Valid \\
\hline $\mathrm{X}_{1}-3$ & 0,823 & 0,349 & Valid \\
\hline $\mathrm{X}_{1}-4$ & 0,755 & 0,349 & Valid \\
\hline $\mathrm{X}_{1}-5$ & 0,780 & 0,349 & Valid \\
\hline $\mathrm{X}_{1}-6$ & 0,777 & 0,349 & Valid \\
\hline $\mathrm{X}_{1}-7$ & 0,655 & 0,349 & Valid \\
\hline $\mathrm{X}_{1}-8$ & 0,802 & 0,349 & Valid \\
\hline $\mathrm{X}_{1}-9$ & 0,754 & 0,349 & Valid \\
\hline $\mathrm{X}_{1}-10$ & 0,863 & 0,349 & Valid \\
\hline $\mathrm{X}_{1}-11$ & 0,798 & 0,349 & Valid \\
\hline $\mathrm{X}_{1}-12$ & 0,799 & 0,349 & Valid \\
\hline $\mathrm{X}_{1}-13$ & 0,740 & 0,349 & Valid \\
\hline $\mathrm{X}_{1}-14$ & 0,776 & 0,349 & Valid \\
\hline $\mathrm{X}_{1}-15$ & 0,731 & 0,349 & Valid \\
\hline
\end{tabular}

Berdasarkan uji validitas menggunakan program statistik diketahui bahwa dari 15 pertanyaan atau pernyataan mengenai bekerja jarak jauh, semua pertanyaan atau pernyataan adalah valid sehingga semua akan dipakai untuk analisis selanjutnya.

Tabel 6. Hasil Uji Validitas Komunikasi

\begin{tabular}{cccl}
\hline $\begin{array}{c}\text { Nomor } \\
\text { Pertanyaan }\end{array}$ & $\begin{array}{c}\boldsymbol{r} \\
\text { hitung }\end{array}$ & $\begin{array}{c}\boldsymbol{r} \\
\text { tabel }\end{array}$ & Keterangan \\
\hline $\mathrm{X}_{2}-1$ & 0,756 & 0.349 & Valid \\
\hline $\mathrm{X}_{2}-2$ & 0,894 & 0.349 & Valid \\
\hline $\mathrm{X}_{2}-3$ & 0,819 & 0.349 & Valid \\
\hline $\mathrm{X}_{2}-4$ & 0,902 & 0.349 & Valid \\
\hline $\mathrm{X}_{2}-5$ & 0,838 & 0.349 & Valid \\
\hline $\mathrm{X}_{2}-6$ & 0,923 & 0.349 & Valid \\
\hline $\mathrm{X}_{2}-7$ & 0,865 & 0.349 & Valid \\
\hline $\mathrm{X}_{2}-8$ & 0,789 & 0.349 & Valid \\
\hline $\mathrm{X}_{2}-9$ & 0,648 & 0.349 & Valid \\
\hline $\mathrm{X}_{2}-10$ & 0,817 & 0.349 & Valid \\
\hline $\mathrm{X}_{2}-11$ & 0,853 & 0.349 & Valid \\
\hline $\mathrm{X}_{2}-12$ & 0,850 & 0.349 & Valid \\
\hline $\mathrm{X}_{2}-13$ & 0,880 & 0.349 & Valid \\
\hline $\mathrm{X}_{2}-14$ & 0,797 & 0.349 & Valid \\
\hline $\mathrm{X}_{2}-15$ & 0,890 & 0.349 & Valid \\
\hline $\mathrm{X}_{2}-16$ & 0,821 & 0.349 & Valid \\
\hline & & & \\
\hline & 0.349 & \\
\hline
\end{tabular}

Berdasarkan uji validitas menggunakan program statistik diketahui bahwa dari 16 pertanyaan atau pernyataan mengenai komunikasi, semua pertanyaan atau pernyataan adalah valid sehingga semua akan dipakai untuk analisis selanjutnya.

Tabel 7. Hasil Uji Validitas Penjadwalan Proyek

\begin{tabular}{cccc}
\hline $\begin{array}{c}\text { Nomor } \\
\text { Pertanyaan }\end{array}$ & $\begin{array}{c}\boldsymbol{r} \\
\text { hitung }\end{array}$ & $\begin{array}{c}\boldsymbol{r} \\
\text { tabel }\end{array}$ & Keterangan \\
\hline $\mathrm{Y} \_1$ & 0,781 & 0.349 & Valid \\
\hline $\mathrm{Y} \_2$ & 0,771 & 0.349 & Valid \\
\hline
\end{tabular}




\begin{tabular}{cccl}
\hline $\begin{array}{c}\text { Nomor } \\
\text { Pertanyaan }\end{array}$ & $\begin{array}{c}\boldsymbol{r} \\
\text { hitung }\end{array}$ & $\begin{array}{c}\boldsymbol{r} \\
\text { tabel }\end{array}$ & Keterangan \\
\hline Y_3 & 0,728 & 0.349 & Valid \\
\hline Y_4 & 0,817 & 0.349 & Valid \\
\hline Y_5 & 0,803 & 0.349 & Valid \\
\hline Y_6 & 0,740 & 0.349 & Valid \\
\hline Y_7 & 0,790 & 0.349 & Valid \\
\hline Y_8 & 0,708 & 0.349 & Valid \\
\hline Y_9 & 0,743 & 0.349 & Valid \\
\hline Y_10 & 0,639 & 0.349 & Valid \\
\hline Y_11 & 0,747 & 0.349 & Valid \\
\hline Y_12 & 0,771 & 0.349 & Valid \\
\hline
\end{tabular}

Berdasarkan uji validitas menggunakan program statistik diketahui bahwa dari 12 pertanyaan atau pernyataan mengenai penjadwalan proyek, semua pertanyaan atau pernyataan adalah valid sehingga semua akan dipakai untuk analisis selanjutnya.

Tabel 8. Hasil Uji Reabilitas Bekerja Jarak Jauh

\begin{tabular}{rr}
\hline Cronbach's Alpha & \multicolumn{1}{c}{ N of Items } \\
\hline 0,948 & 15 \\
\hline
\end{tabular}

Tabel 9. Hasil Uji Reabilitas Komunikasi

\begin{tabular}{rr}
\hline Cronbach's Alpha & N of Items \\
\hline 0,970 & 16 \\
\hline
\end{tabular}

Tabel 10. Hasil Uji Realbilitas Penjadwalan

\begin{tabular}{rr}
\hline Cronbach's Alpha & N of Items \\
\hline 0,929 & 12 \\
\hline
\end{tabular}

Dari ketiga tabel di atas didapat hasil bahwa nilai Cronbach's alpha dari komunikasi, penyediaan sarana, dan efektivitas kerja > 0,60 jadi semua indikator dinyatakan konsisten atau dapat dipercaya sebagai alat ukur.

\section{Analisis hubungan antara bekerja jarak jauh dengan penjadwalan proyek}

Tabel 11. Perhitungan Korelasi Hubungan Bekerja Jarak Jauh dengan Penjadwalan Proyek

\begin{tabular}{|c|c|c|c|}
\hline & & $\begin{array}{c}\text { Bekerja } \\
\text { jarak jauh }\end{array}$ & $\begin{array}{c}\text { Penjadwalan } \\
\text { di proyek } \\
\text { kawan lama } \\
\text { retail }\end{array}$ \\
\hline \multirow{3}{*}{$\begin{array}{l}\text { Bekerja } \\
\text { jarak } \\
\text { jauh }\end{array}$} & $\begin{array}{l}\text { Pearson } \\
\text { Correlation }\end{array}$ & 1 & $.799 * *$ \\
\hline & $\begin{array}{l}\text { Sig. (2- } \\
\text { tailed) }\end{array}$ & & .000 \\
\hline & $\mathrm{N}$ & 32 & 32 \\
\hline \multirow{3}{*}{$\begin{array}{l}\text { Penjadw } \\
\text { alan } \\
\text { proyek }\end{array}$} & $\begin{array}{l}\text { Pearson } \\
\text { Correlation }\end{array}$ & $.799 * *$ & 1 \\
\hline & $\begin{array}{l}\text { Sig. (2- } \\
\text { tailed) }\end{array}$ & .000 & \\
\hline & $\mathrm{N}$ & 32 & 32 \\
\hline
\end{tabular}

Berdasarkan hasil perhitungan korelasi seperti yang tertera di tabel 11, diketahui bahwa nilai koefisien korelasi sesuai dengan uji korelasi Pearson adalah 0,799 yang artinya bahwa hubungan korelasi antara bekerja jarak jauh dengan penjadwalan Proyek mempunyai hubungan cukup erat dan memberikan efek positif. Jadi walaupun bekerja jarak jauh, penjadwalan proyek juga berjalan sesuai dengan target yang di tentukan.

Tabel 12. Perhitungan Koefisien Determinasi Hubungan Bekerja Jarak Jauh dengan Penjadwalan Proyek

\begin{tabular}{crrr}
\hline $\boldsymbol{R}$ & $\begin{array}{c}\boldsymbol{R} \\
\text { Square }\end{array}$ & $\begin{array}{c}\text { Adjusted } R \\
\text { Square }\end{array}$ & $\begin{array}{l}\text { Std. Error of } \\
\text { the Estimate }\end{array}$ \\
\hline $.799 \mathrm{a}$ & .639 & .627 & 5.22298 \\
\hline
\end{tabular}

Berdasarkan hasil perhitungan regresi tabel 12 diketahui bahwa nilai koefisien determinasi $\mathrm{R} 2=0,639$ atau 63,9\%. Hal ini menunjukkan bahwa sebesar $63.9 \%$ penjadwalan proyek dipengaruhi oleh 
bekerja jarak jauh dan sisanya dipengaruhi oleh hal lain.

Tabel 13. Perhitungan Uji $t$ dan Koefisien Regresi Hubungan Bekerja Jarak Jauh dengan Penjadwalan Proyek

\begin{tabular}{lrrrrr}
\hline Model & \multicolumn{1}{c}{$\begin{array}{c}\text { Unstandardi } \\
\text { zed } \\
\text { Coefficients }\end{array}$} & $\begin{array}{c}\text { Standa } \\
\text { rdized } \\
\text { Coeffic } \\
\text { ients }\end{array}$ & $t$ & Sig. \\
\cline { 2 - 5 } & B & $\begin{array}{c}\text { Std. } \\
\text { Error }\end{array}$ & Beta & & \\
\hline (Constant) & 2.623 & 5.671 & & .462 & .647 \\
\hline $\begin{array}{l}\text { Bekerja } \\
\text { jarak jauh }\end{array}$ & .782 & .107 & .799 & 7.289 & .000 \\
\hline
\end{tabular}

Berdasarkan hasilkan uji $\mathrm{t}$ seperti yang tertera di tabel 13 diketahui bahwa nilai thitung $=7,289$. Hal ini menunjukkan bahwa thitung > ttabel (1.69726) berarti koefisien regresi signifikan sehingga Ho1 ditolak. Maka dapat disimpulkan terdapat hubungan positif dan signifikan pada taraf kepercayaan 95\% antara bekerja jarak jauh dan penjadwalan proyek. Dari tabel IV.22 juga didapat nilai konstanta $=0,782$. Sehingga didapat persamaan sebagai berikut:

$$
\mathrm{Y}=2,623+0.782 \mathrm{X} 1
$$

Persamaan tersebut berarti apabila bekerja jarak jauh bernilai 0 , maka penjadwalan proyek akan bernilai positif sebesar 2,623. Hal ini menunjukkan ada pengaruh yang berbanding lurus antara bekerja jarak jauh dan penjadwalan proyek.

\section{Analisis hubungan antara komunikasi dengan penjadwalan proyek}

Tabel 14. Perhitungan Korelasi Hubungan Komunikasi dengan Penjadwalan Proyek

\begin{tabular}{llrr}
\hline & & $\begin{array}{c}\text { Komuni } \\
\text { kasi }\end{array}$ & $\begin{array}{c}\text { Penjadwala } \\
\text { n di proyek } \\
\text { kawan lama } \\
\text { retail }\end{array}$ \\
\hline \multirow{2}{*}{$\begin{array}{l}\text { Komuni } \\
\text { kasi }\end{array}$} & Pearson & 1 & $.804^{* *}$ \\
\cline { 2 - 4 } & Correlation & & \\
\hline
\end{tabular}

\begin{tabular}{llrr}
\hline & $\mathrm{N}$ & 32 & 32 \\
\hline & Pearson & $.804^{* *}$ & 1 \\
Penjadw & Correlation & & \\
\cline { 2 - 4 } $\begin{array}{l}\text { alan } \\
\text { proyek }\end{array}$ & Sig. (2-tailed) & .000 & 32 \\
\cline { 2 - 4 } & $\mathrm{N}$ & 32 & \\
\hline
\end{tabular}

Berdasarkan hasil perhitungan korelasi seperti yang tertera di tabel 14 di atas, diketahui bahwa nilai koefision korelasi sesuai dengan uji korelasi pearson adalah 0,804 yang artinya bahwa hubungan korelasi antara komunikasi dengan penjadwalan Proyek mempunyai hubungan cukup erat dan memeberikan efek positif. Jadi apabila atasan dan rekan kerja lebih sangat jelas memberikan arahan maka penjadwalan proyek akan berjalan sesuai dengan target yang telah di tentukan.

Tabel 15. Perhitungan Koefisien Determinasi Hubungan Bekerja Jarak Jauh dengan Penjadwalan Proyek

\begin{tabular}{crrr}
\hline$R$ & \multicolumn{2}{c}{$\boldsymbol{R}$} & \multicolumn{2}{c}{ Adjusted $R$} & Std. Error of the \\
& Square & Square & Estimate \\
\hline $.801^{\mathrm{a}}$ & .647 & .635 & 5.16755 \\
\hline
\end{tabular}

Berdasarkan hasil perhitungan regresi seperti yang tertera di tabel 15 diketahui bahwa nilai koefisien determinasi $\mathrm{R} 2=$ 0,647 atau $64,7 \%$. Hal ini menunjukkan bahwa sebesar $63.9 \%$ penjadwalan proyek dipengaruhi oleh komunikasi dan sisanya di pengaruh oleh hal lain.

Tabel 16. Perhitungan Uji t dan Koefisien Regresi Hubungan Bekerja Jarak Jauh dengan Penjadwalan Proyek

\begin{tabular}{|c|c|c|c|c|c|}
\hline & \multicolumn{2}{|c|}{$\begin{array}{c}\text { Unstandardize } \\
\text { d Coefficients }\end{array}$} & \multirow{2}{*}{$\begin{array}{c}\begin{array}{c}\text { Stand } \\
\text { ardize } \\
d \\
\text { Coeffi } \\
\text { cients }\end{array} \\
\text { Beta }\end{array}$} & \multirow[t]{2}{*}{$t$} & \multirow[t]{2}{*}{ Sig. } \\
\hline & $B$ & $\begin{array}{l}\text { Std. } \\
\text { Error }\end{array}$ & & & \\
\hline $\begin{array}{l}\text { (Const } \\
\text { ant) }\end{array}$ & 4.201 & 5.368 & & .783 & .440 \\
\hline
\end{tabular}




\begin{tabular}{llllll}
$\begin{array}{l}\text { Komun } \\
\text { ikasi }\end{array}$ & .649 & .088 & .804 & 7.411 & .000 \\
\hline
\end{tabular}

Berdasarkan hasilkan uji $\mathrm{t}$ seperti yang tertera di tabel IV. 25 diketahui bahwa nilai thitung $=7,411$. Hal ini menunjukkan bahwa thitung > ttabel (1.69726) berarti koefisien regresi signifikan sehingga Ho2 ditolak. Maka dapat disimpulkan terdapat hubungan positif dan signifikan pada taraf kepercayaan 95\% antara komunikasi dan efektivitas. Dari tabel IV.25 juga didapat nilai konstanta $=0,649$. Sehingga didapat persamaan sebagai berikut:

$$
\mathrm{Y}=4,201+0.649 \mathrm{X} 2
$$

Persamaan tersebut berarti apabila komunikasi bernilai 0 , maka penjadwalan proyek akan bernilai positif sebesar 4,201. Hal ini menunjukkan ada pengaruh yang berbanding lurus antara komunikasi dan penjadwalan proyek.

\section{Analisis hubungan antara bekerja jarak jauh dan komunikasi dengan penjadwalan proyek}

Tabel 17. Perhitungan Koefisien Korelasi dan Koefisien Determinasi Hubungan Bekerja Jarak Jauh dan Komunikasi dengan Penjadwalan Proyek

\begin{tabular}{crrr}
\hline $\boldsymbol{R}$ & \multicolumn{2}{c}{$\boldsymbol{R}$} & \multicolumn{2}{c}{ Adjusted } & Std. Error of the \\
& Square & $\boldsymbol{R}$ Square & \multicolumn{1}{c}{ Estimate } \\
\hline $.845^{\mathrm{a}}$ & .714 & .695 & 4.72517 \\
\hline
\end{tabular}

Berdasarkan hasil perhitungan regresi seperti yang tertera di tabel 17 diketahui bahwa nilai koefisien korelasi $\mathrm{R}=0,845$ yang artinya hubungan korelasi antara bekerja jarak jauh dan komunikasi secara bersama-sama dengan penjadwalan proyek mempunyai hubungan yang cukup erat. Tetapi hal ini tetap mencerminkan adanya hubungan yang positif dengan penjadwalan proyek. Pada tabel 17 juga diketahui bahwa nilai determinasi $\mathrm{R} 2=0,714$ atau $71,4 \%$. Hal ini menunjukkan bahwa sebesar $71,4 \%$ penjadwalan proyek di pengaruh oleh bekerja jarak jauh dan komunikasi, sedangkan sisa persentasenya dipengaruhi oleh hal lain.

Tabel 18. Perhitungan Uji $F$ Hubungan antara Bekerja Jarak Jauh dan Komunikasi dan Penjadwalan Proyek

\begin{tabular}{rrrrr}
\hline $\begin{array}{c}\text { Sum of } \\
\text { Squares }\end{array}$ & $\boldsymbol{d} \boldsymbol{c}$ & $\begin{array}{c}\text { Mean } \\
\text { Square }\end{array}$ & $\boldsymbol{F}$ & Sig. \\
\hline 1620.230 & 2 & 810.115 & 36.284 & $.000^{\mathrm{b}}$ \\
\hline 647.489 & 29 & 22.327 & & \\
\hline 2267.719 & 31 & & & \\
\hline
\end{tabular}

Berdasarkan hasil perhitungan uji $\mathrm{F}$ seperti yang tertera di tabel 18 diketahui bahwa nilai Fhitung $=36,284$. Hal ini menunjukkan bahwa Fhitung $>$ Ftabel $(3,33)$ berarti koefisien regresi signifikan sehingga Ho3 ditolak. Maka dapat disimpulkan terdapat hubungan positif dan signifikan pada taraf kepercayaan 95\% antara bekerja jarak jauh dan komunikasi dengan penjadwalan proyek.

Tabel 19. Perhitungan Uji F dan Koefisien Regresi Hubungan antara Bekerja Jarak Jauh dan Komunikasi dan Penjadwalan Proyek

\begin{tabular}{lccccc}
\hline Model & $\begin{array}{c}\text { Unstandardiz } \\
\text { ed Coefficients }\end{array}$ & $\begin{array}{c}\text { Stand } \\
\text { ardize } \\
\boldsymbol{d}\end{array}$ & \multicolumn{1}{c}{$\begin{array}{c}\text { d } \\
\text { Coeffi } \\
\text { cients }\end{array}$} & Sig \\
\cline { 2 - 5 } & B & $\begin{array}{c}\text { Std. } \\
\text { Error }\end{array}$ & Beta & & \\
& & & & \\
\hline $\begin{array}{l}\text { (Consta } \\
\text { nt) }\end{array}$ & -1.012 & 5.296 & & -.191 & .850 \\
\hline $\begin{array}{l}\text { Bekerja } \\
\text { jarak } \\
\text { jauh }\end{array}$ & .424 & .162 & .434 & 2.623 & .014 \\
\hline $\begin{array}{l}\text { Komuni } \\
\text { kasi }\end{array}$ & .369 & .133 & .457 & 2.767 & .010 \\
\hline
\end{tabular}

Dari tabel 19 juga didapat nilai konstanta = 1,012 dan nilai koefisien regresi $=0,424$ untuk bekerja jarak jauh dan 0.369 untuk komunikasi. Sehingga didapat persamaan sebagai berikut: 


$$
\mathrm{Y}=-1,012+0,424 \mathrm{X} 1+0,369 \mathrm{X} 2
$$

Persamaan tersebut berarti apabila bekerja jarak jauh dan komunikasi bernilai 0, maka penjadwalan proyek akan bernilai negatif sebesar -1,012 dengan kata lain dengan setiap jika tidak ada peningkatan dalam bekerja jarak jauh dan komunikasi maka penjadwalan proyek tidak akan berjalan sesuai dengan target yang sudah di tentukan.

\section{Koefisien determinasi parsial}

Tabel 20. Koefisien Determinasi Parsial

\begin{tabular}{cccc}
\hline Variabel & $\boldsymbol{b}$ & $\begin{array}{c}\text { Correl } \\
\text { ation }\end{array}$ & $\begin{array}{c}\text { Koefisie } \\
\text { Determi } \\
\text { nasi } \\
\text { Parsial }\end{array}$ \\
\hline $\begin{array}{c}\text { Bekerja } \\
\text { jarak jauh }\end{array}$ & 0,434 & 0,799 & $34,67 \%$ \\
\hline $\begin{array}{c}\text { Komunika } \\
\text { si }\end{array}$ & 0,457 & 0,804 & $36,74 \%$ \\
\hline & Total & & $71,41 \%$ \\
\hline
\end{tabular}

Berdasarkan tabel di atas, diketahui besarnya koefisien determinasi parsial variabel komunikasi terhadap penjadwalan proyek di Kawan Lama Retail adalah sebesar $36,74 \%$. Hal ini menunjukkan bahwa variabel komunikasi lebih tinggi korelasi nya dibandingkan dengan variabel bekerja jarak jauh.

\section{PEMBAHASAN HASIL PENELITIAN}

Dalam hasil penelitian ini didapatkan beberapa pembahasan mengenai hubungan bekerja jarak jauh, Komunikasi, dan Penjadwalan Proyek adalah sebagai berikut:

1. Hubungan antara Bekerja Jarak Jauh dengan Penjadwalan Proyek

Bekerja jarak jauh merupakan kemampuan untuk melakukan pekerjaan di lokasi selain dari kantor resmi, seperti dari rumah, café dan lain-lain yang dilakukan secara rutin, teratur lebih dari satu hari dalam sepekan. Pekerjaan yang dapat dikerjakan dengan cara jarak jauh adalah pekerjaan yang mengelola informasi secara rutin, pekerjaan yang membutuhkan aktivitas banyak berpindah tempat, serta tugas-tugas profesional atau pekerjaan yang membutuhkan pengetahuan spesifik untuk mengerjakannya, biasanya hanya karyawan yang sering mengakses komputer atau menggunakan telepon saja. Dari segi perusahaan menerapkan bekerja jarak jauh dapat mengurangi biaya yang terkait dengan akomodasi fisik karyawan, seperti biaya properti dan pemeliharaan properti. Dari sudut pandang karyawan, bekerja jarak jauh dianggap sebagai sebuah hak istimewa dimana mereka memiliki kesempatan bekerja sekaligus mengatur pekerjaan rumah tangga, mengurus anak dalam keadaan darurat, pengurangan perjalanan ke kantor, pengurangan tingkat ketidakhadiran dan sebagainya. Hal ini dapat menimbulkan perasaan rasa tanggung jawab yang lebih besar sehingga mereka bekerja lebih lama daripada karyawan lain yang bekerja di kantor pusat. Menerapkan bekerja jarak jauh membutuhkan tingkat kepercayaan yang tinggi antara atasan dengan karyawan. Atasan yang belum mampu mengontrol pekerjaan karyawan yang tidak di tempat akan lebih sulit. Penting bagi atasan mempunyai mekanisme kontrol dan pekerjaan jarak jauh yang di atur dalam perjanjian kerja. Bekerja jarak jauh atau bekerja tidak harus di kantor menjadi solusi ketika suatu pekerjaan tidak memungkinkan untuk dilakukan di tempat kerja. Bekerja jarak jauh juga dimaksudkan untuk memberikan keleluasaan bagi pegawai dalam menyelesaikan pekerjaannya dimana saja dan kapan saja, dengan pemanfaatan teknologi komunikasi dan informasi modern. Bagi instansi/perusahaan produktifitas dan efisiensi operasional menjadi pendorong untuk menerapkan keleluasaan kerja (flexible work). Kerja leluasa mempunyai peluang menguntungkan bagi pegawai dan juga organisasi melalui dukungan perilaku kerja positif seperti komitmen, motivasi dan kepuasan kerja, dan berkinerja baik 
Berdasarkan hasil responden yang di bagikan bagi karyawan yang bekerja di Kawan Lama Retail, Bekerja jarak jauh sebenarnya tidak terlalu diminati oleh karyawan Kawan Lama, tetapi walaupun dengan bekerja jarak jauh karyawan tetap dapat bekerja sama dengan baik dengan rekan kerja, dan lebih efektif dan cepat dalam mengerjakan pekerjaan saat bekerja jarak jauh, tetapi halangan yang sering terjadi adalah kurangnya fasilitas yang memadai seperti adanya gangguan pada komputer atau laptop, internet yang kurang baik yang menyebabkan pekerjaan menjadi tertunda di bandingkan bekerja di kantor yang mempunyai kualitas internet dan perangkat komputer yang lebih baik.

Berdasarkan uraian di atas, terdapat hubungan positif dan signifikan antara bekerja jarak jauh dan penjadwalan proyek. Indikator dalam variabel bekerja jarak jauh mempunyai hubungan dengan indikator dalam variabel penjadwalan. Hubungan korelasi antara bekerja jarak jauh dengan Penjadwalan Proyek mempunyai hubungan yang cukup erat dan bernilai positif. Walaupun bekerja jarak jauh proses pelaksanaan penjadwalan proyek tetap berjalan sesuai dengan target yang telah di tentukan.

2. Hubungan antara Komunikasi dengan Penjadwalan Proyek

Komunikasi yang efektif dapat terjadi apabila pesan tersebut dapat di pahami sesuai dengan yang diinginkan oleh pengirim pesan. Masalah yang dialami dalam sumber daya manusia disebabkan oleh komunikasi yang buruk antara pengirim dan penerima pesan. Dalam proses komunikasi dibutuhkan informasi mengenai proyek akan sampai tepat pada waktunya. Penggunaan teknologi dan penanganan informasi yang sangat penting agar dapat didistribusikan dengan efektif dan tepat waktu. Berdasarkan hasil responden yang di bagikan kepada karyawan yang bekerja di Kawan Lama Retail, Berdiskusi dengan rekan kerja saat mengalami kesulitan, terbuka menerima pendapat, memberikan informasi yang jelas dan melaporkan setiap hasil pekerjaan kepada atasan merupakan hal penting dalam pelaksanaan komunikasi. Komunikasi merupakan salah satu dari kegiatan sehari-hari yang terhubung dengan semua kegiatan kemanusiaan, setiap aspek kehidupan kita selalu dipengaruhi oleh komunikasi kita dengan orang lain, komunikasi merupakan sebuah proses menyamakan dua atau beberapa hal mengenai kekuasaan terhadap seseorang atau beberapa orang, komunikasi di katakan berhasil jika komunikasi merupakan pertukaran sebuah pemikiran atau gagasan. Asumsi dalam definisi ini adalah bahwa sebuah pemikiran atau gagasan berhasil ditukarkan, ada yang berpendapat bahwa komunikasi merupakan sebuah proses dalam penyampaian pesan dari komunikator kepada komunikan melalui saluran tertentu

Berdasarkan uraian di atas, terdapat hubungan positif dan signifikan antara komunikasi dan penjadwalan proyek. Indikator dalam variabel komunikasi mempunyai hubungan dengan indikator dalam variabel penjadwalan. Hubungan korelasi antara komunikasi dengan Penjadwalan Proyek mempunyai hubungan yang cukup erat dan bernilai positif. Jadi jika atasan dan rekan kerja memberikan informasi yang jelas maka penjadwalan akan sesuai dengan target yang ada.

3. Hubungan antara Bekerja Jarak Jauh dan Komunikasi dengan Penjadwalan Proyek

Bekerja jarak jauh atau di sebut sebagai telecommuting adalah pekerjaan yang dilakukan oleh seseorang khusus, atau hanya waktu tertentu, pada sebuah lokasi jauh dari kantor, menggunakan media telekomunikasi sebagai alat kerja. Bekerja jarak jauh juga dimaksudkan untuk memberikan keleluasaan bagi karyawan dalam menyelesaikan pekerjaan dimana saja dan kapan saja dengan pemanfaatan teknologi komunikasi modern tanpa mempengaruhi target pekerjaan yang ada. Komunikasi juga dapat diartikan sebagai transfer informasi atau pesan dari pengirim pesan sebagai komunikator dan kepada 
penerima sebagai komunikan. Dalam proses komunikasi tersebut bertujuan untuk mencapai saling pengertian antara kedua pihak yang terlibat dalam proses komunikasi. Komunikasi yang jelas akan membuat pekerjaan menjadi lebih baik dan benar serta meminimalisir kesalahankesalahan yang ada. Penjadwalan proyek merupakan pengalokasian waktu yang tersedia untuk menyelesaikan suatu proyek hingga tercapai hasil optimal dengan mempertimbangkan keterbatasanketerbatasan yang ada seperti biaya dan waktu

Berdasarkan uraian diatas, diketahui bahwa terdapat hubungan positif dan signifikan antara bekerja jarak jauh dan komunikasi secara bersama-sama dengan penjadwalan proyek. Indikator dalam variabel bekerja jarak jauh dan indikator dalam variabel komunikasi secara bersama-sama mempunyai hubungan dengan indikator dalam penjadwalan proyek. Hubungan korelasi antara bekerja jarak jauh dan Komunikasi secara bersama-sama dengan proyek penjadwalan mempunyai hubungan positif dan signifikan, dengan kata lain jika tidak ada peningkatan dalam bekerja jarak jauh dan komunikasi yang baik maka penjadwalan tidak akan memenuhi target yang ada

\section{KESIMPULAN}

Dari hasil penelitian mengenai analisis hubungan antara bekerja jarak jauh dan komunikasi dengan penjadwalan proyek di Kawan Lama Retail dapat disimpulkan sebagai berikut:

1. Hubungan antara bekerja jarak jauh dengan penjadwalan proyek mempunyai hubungan cukup erat dan memberikan efek positif. Jadi meskipun bekerja jarak jauh, karyawan tetap dapat mengerjakan tugas dengan efektif, tepat dan dapat bekerja sama dengan baik dengan rekan kerja sehingga penjadwalan proyek di Kawan Lama Retail akan berjalan sesuai dengan target yang telah di tentukan. Terdapat hubungan positif dan signifikan pada taraf kepercayaan 95\% antara bekerja jarak jauh dengan penjadwalan proyek di Kawan Lama Retail, dengan koefisien determinasi parsial variabel sebesar $34,67 \%$.

2. Hubungan antara komunikasi dengan penjadwalan proyek mempunyai hubungan cukup erat dan memberikan efek positif. Jadi apabila atasan dan rekan kerja memberikan arahan dengan jelas maka penjadwalan proyek akan berjalan sesuai dengan target yang telah di tentukan Terdapat hubungan positif dan signifikan pada taraf kepercayaan 95\% antara komunikasi dengan penjadwalan proyek di Kawan Lama Retail, dengan koefisien determinasi parsial variabel sebesar $36,74 \%$.

3. Hubungan antara bekerja jarak jauh dan komunikasi secara bersama-sama dengan penjadwalan proyek mempunyai hubungan cukup erat dan memberikan efek positif. Terdapat hubungan positif dan signifikan pada taraf kepercayaan 95\% antara bekerja jarak jauh dan komunikasi dan penjadwalan proyek di Kawan Lama Retail, dengan koefisien determinasi parsial variabel sebesar $71.41 \%$.

\section{DAFTAR PUSTAKA}

[1] Ardial (2018) Fungsi Komunikasi Organisasi: Studi Kasus Tentang Fungsi Komunikasi Organisasi Terhadap Kinerja Pegawai., Medan, Penerbit Lembaga Penelitian dan Penulisan Ilmiah Aqli.

[2] Avellino, Marie, 2005. An Enabling Framework for Telework. Research Project for The Employment and Training Corporation, Hal Far.

[3] Darwis, Darwanto (2012), Hubungan Kepemimpinan dan Komunikasi Pelaksana Dengan Kinerja Operator Alat Pancang di PT XYZ, Jakarta, Universitas Tarumanagara

[4] Heathfield, Susan M (2019) Flexible Working hours 7 benefits your 
business is missing out on, https://www.thebalancecareers.com/ advantages-and-disadvantages-offlexible-work-schedules-1917964

[5] Husen, Abrar (2009) Manajemen Proyek., Yogyakarta, Penerbit Andi.

[6] Kevan R. Shafizadeh, P.E, Debbie A. Niemeier, P.E, Patricia L. Mokhtarian dan Ilan Salomon (2007), Costs and Benefits of Home-Based Telecommuting: A Monte Carlo Simulation Model Incorporating Telecommuter, Employer, and Public Sector Perspectives, Jurnal ASCE

[7] Liliweri, Alo (2011) Komunikasi: Serba ada serba makna, Jakarta, Penerbit Prenada Media Group.

[8] Littlejhon W.S dan Foss A.K (2018) Theories of Human Communication 9th ed., Jakarta, Penerbit Salemba Humanika.

[9] Mungkasa, Oswar (2020) Bekerja jarak jauh (telecommuting): Konsep, Penerapan dan Pembelajaran, Jurnal Bappenas Working Papers, Vol 3

[10] Nilles, J.M (1998), Traffic Reduction by Telecommuting: A Status Review and Selected Bibliography. Transportation Research, 22A, pp. 301.317

[11] Ohio University,2015. Telecommuting Can Save Business Money. Online Master of Business Administration. https://onlinemasters.ohio.edu/blog/ how-telecommuting-cansavebusinesses-money/

[12] Robbins P Stephen dan Judge A Timothy (2008). Perilaku Organisasi Edisi 12, Jakarta, Penerbit Salemba Empat

[13] Sadida, Nuri. (2016). Mengikat Karyawan dengan Telecommuting (Studi Keterikatan kerja karyawan telecommuting). Jurnal Psikogenesis, Vol 4

[14] Sukoco, Badri Munir (2007). Manajemen Administrasi perkantoran Modern, Jakarta, Penerbit Erlangga
[15] Suprapto, Tommy (2009) Pengantar Teori \& Manajemen Komunikasi, Jakarta, Penerbit Salemba Humanika, Penerbit MedPress. 
